\title{
Facilitation of Entrepreneurial Discovery Processes by Policymakers: an Actionable Definition of Roles and Challenges
}

\author{
Miren Estensoro $^{1}$ (D) $\cdot$ Miren Larrea $^{1}$ D
}

Received: 22 March 2021 / Accepted: 12 January 2022

(C) The Author(s) 2022

\begin{abstract}
The objective of this paper is to contribute to the academic literature with an actionable framework of the roles of policy makers in entrepreneurial discovery processes (EDP) in the context of smart specialisation strategies (S3). The methodology used to define such roles is action research and, consequently, they are the result of learning and negotiation between policy makers and other territorial stakeholders facilitated by action researchers. The case study is based in the Bilbao Next Lab project (Bilbao, Basque region, Spain) where this methodology was chosen because policy makers wanted to explore EDP through collaborative governance. The key findings have been integrated in a framework named as the six roles of facilitative policymakers in EDPs. Its actionability is visible in the connection of the framework with the dilemmas, difficulties, and problems faced by policy makers when facilitating EDP processes. The framework is presented together with a discussion on the relevance of including tailored capacity development processes for policymakers as part of the EDP. The paper concludes with a final reflection on how the need for a facilitative role of policymakers also requires a transformation of research methodologies by social researchers.
\end{abstract}

Keywords Smart specialisation strategy $\cdot$ Entrepreneurial discovery process · Facilitation · Capabilities · Policy process $\cdot$ Action research

\section{Introduction}

Entrepreneurial discovery processes (EDP) are one of the pillars of smart specialisation strategies (S3). S3 is a research and innovation agenda for regional economic transformation including a bottom-up, place-based approach to regional

Miren Estensoro

mestenso@orkestra.deusto.es

Miren Larrea

miren.larrea@orkestra.deusto.es

1 Orkestra-Basque Institute of Competitiveness and University of Deusto, Mundaiz, 50,

20012 San Sebastian, Spain 
development and originated from the aim of closing the productivity gap between Europe and key trading partners such as China and USA (Foray et al., 2012). The achievement of an effective 'collaborative governance' within S3 has been introduced with a great emphasis (Lepore \& Spigarelli, 2018), and the concept of EDP is based on this governance approach. EDP is an inclusive and interactive mainly bottom-up process in which participants form the quadruple helix engage with each other to identify potential new activities and competitive advantages as well as its challenges and priorities, all to be tackled throughout the implementation of S3 (Müür 2021; Esparza-Masana, 2021; Santini et al., 2015). As Esparza-Masana (2021) argues, EDP is a strategy to avoid a 'one-size-fits all' in order to maximise the effectiveness of the strategy.

Moreover, the European Union enters now a new multiannual programming period from 2021 until 2027 including new strategies for sustainable, resilient, just, and inclusive growth. S3 will continue to play an important role under the policy objective of a smarter Europe. Actions to manage industrial transition and measures for international collaboration have been introduced to ensure continuity and impact. Moreover, the S3 concept will be adapted by embedding the directionality of the 2030 Agenda and goals of systemic transformation underpinning the Sustainable Development Goals. Within this framework, the Commission is developing the concept of Smart Specialisation Strategies for Sustainability (S4) defined as place-based innovation-led transformation for growth and sustainability. S4 will then combine top-down directionality with bottom-up processes of EDP, and the involvement of local actors will continue to be a key feature of place-based innovation processes (McCann \& Soete, 2020).

However, as Esparza-Masana (2021) argues when referring to the challenges of moving from 'S3 1.0 into S3 2.0', the implementation of EDP is still a difficult task. Actually, one of the major challenges of smart specialisation strategies today is the implementation of EDPs (Roman \& Nyberg, 2017). Consequently, further study is needed as to the specific roles that governments play in this endeavour (Aranguren et al., 2018; Lepore \& Spigarelli, 2018; Müür, 2021).

The problem addressed in this paper is that although the literature on smart specialisation describes the features of EDPs and points out the need for the public sector to take on a new role in developing them, most contributions fall short when specifying what this role should consist of in. Many guides and handbooks offer insights to policymakers involved in EDPs (Mieszkowski \& Kardas, 2015; Periánez-Forte et al., 2016; Gianelle et al., 2016; Marinelli \& Periánez-Forte, 2017; Detterbeck, 2018). While some of them focus on specific operationalisation challenges (Todeva \& Ketikidis, 2017; Vivanco et al., 2016; Martínez López \& Palazuelos Martínez, 2015), others offer a holistic process approach (Roman \& Nyberg, 2017). Müür (2021), for example, attempts to do so by analysing the role of intermediary agents who facilitate interaction among territorial actors in Estonia and Finland. However, Müur coincides with Carayannis and Rakhmatullin (2014) and Lepore and Spigarelli (2018) when arguing that literature on smart specialisation underlines the importance of considering the territorial strategic planning and multi-actor collaboration capability in order to advance, but 'less attention has been put on how such coordination is organised or what it should look like' (p. 28). 
Hence, it can be stated that the specific roles of policymakers within EDPs have not been comprehensively analysed and moreover, that the literature on EDP lacks actionable knowledge developed about these specific roles.

The novelty of the framework and analysis of this paper is that it takes concepts already shared in the literature and integrates them in a knowledge co-generation process based in action research. This means that policy makers and researchers worked together in the context of policy making, simultaneously generating and applying knowledge. Therefore, the knowledge generated is both more contextual and more actionable. The novelty, thus, is not in the generic roles we share, but in the dilemmas, efforts, tensions, needs, power issues, challenges, risks, implicit conflicts, and difficulties we connect to these roles, which increase their actionability. Our contribution is oriented to researchers and policy makers interested not exclusively in the theoretical or conceptual discussion of EDP, but also in how they can address its challenges together.

Our rationale is thus that there is literature on facilitating territorial development processes that can be adapted to the specificities of the EDP and help fill this gap in the smart specialisation literature; however, there is no literature on what makes these roles actionable. Coherently, we define a twofold research question: What are the roles of policymakers in facilitating EDP processes? What are the features that make these roles actionable?

The case study used to test this framework is the urban smart specialisation strategy of the city of Bilbao (Basque Country, Spain), where policymakers of the city council and the city development agency (Bilbao Ekintza) have experimented with this role in the context of an action research project. Based on this research results, we propose here an analytical framework for facilitating EDP processes by policymakers, which we have called the six roles of facilitative policymakers in EDPs. Moreover, by using action research as the methodological approach, the case contributes to the discussion by Santini et al. (2015) about the challenge of bridging the gap between 'thinkers' and 'doers' in EDPs. As these authors underline, the EDP is an opportunity to fill this gap that can also be seen in many other fields.

The remainder of this paper is organised as follows: in the next section, we share our theoretical framework and argue that policymakers need to reformulate their role in EDPs. A conceptual section on this new role follows, together with a description of the case. We then present the discussion of the case together with the conclusions.

\section{Entrepreneurial Discovery Processes: in Search of a New Role for Policymakers in Dialogue with Firms and Entrepreneurs}

Policymakers involved in smart specialisation are expected to change the dynamics of complex structural systems so that they are in harmony with the smart specialisation and their learning nature (Capello \& Lenzi, 2016, p. 15). Some of the implementation problems of 'S3 1.0' (Esparza-Masana, 2021) are said to derive from the difficulties that governments encounter when trying to renew their role and transform into an entrepreneurial public sector (Landabaso, 2014; Mazzucato, 2013). Landabaso (2014), for instance, argues for a public sector capable of taking risks and experimenting, one which is professional, accountable, and that works with the right system of incentives to achieve the common good. Governments are expected 
to be public entrepreneurs with the capacity to avoid some of the past mistakes made in past industrial and innovation policies when facilitating EDPs (Ahner \& Landabaso, 2011; Landabaso, 2014; Lepore \& Spigarelli, 2018; Martínez López \& Palazuelos Martínez, 2015). In this regard, public sector innovation cannot be the only means to build smart public administrations that are better suited to the rationale of new place-based development policies (Morgan, 2017). Instead, what is called for is to develop collaborative policy-making approaches that encourage policymakers to become bolder in their approach to innovation (Gonzalez et al., 2013; Lepore \& Spigarelli, 2018), to be open to change and knowledge exchange (Bonomi et al., 2020), and to facilitate multi-stakeholder cooperation and collaborative governance in the context of EDPs (Carayannis \& Rakhmatullin, 2014; Esparza-Masana, 2021; Müür, 2021).

The initial contributions, made by Austrian economists such as Kirzner (1997), presented entrepreneurial discovery as a concept that raises awareness about the relevance of connecting demand and supply in technological domains. Hausmann and Rodrik (2003) consider discovery processes as a learning experience that fosters economic development. More recently, smart specialisation has been said to require decentralised discovery processes for identifying new opportunities, potential new activities, and competitive advantages and as 'an integral part of political action' (Foray, 2016, p. 1433), 'based on an inclusive and evidence-based process driven by stakeholders' engagement and attention to market dynamics' (Gianelle et al., 2016).

According to Foray (2016), entrepreneurship involves a broad range of stakeholders in the innovation process, that is to say, actors from the knowledge production system, private firms, and society, who are not only based in the region itself but also elsewhere. In that way, firms and entrepreneurs would participate in the policy process together with policy makers and other actors from the quadruple helix, beyond the triple helix that is no longer enough (Foray et al., 2012: 21). This collaborative governance model includes then the civic society for being the consumers of innovation or innovation users (Lepore \& Spigarelli, 2018; Carayannis \& Rakhmatullin, 2014; Höglund \& Lingot, 2018).

Discovery means that all the entrepreneurial actors involved discover a new domain of market and technology opportunity and not an 'ex-post' evaluation of a predetermined set of goals (Foray, 2016, p. 1433). This is precisely one of the challenging features of EDPs for policymakers, as they need to engage in discovery processes without a predetermined result in mind. As Allen (2019) suggests, "the problem of implementing innovation policies (such as S3) is itself a discovery process" (p. 205), and flexibility of adaptation is necessary (Bramwell et al., 2019). Concretely, an EDP is about policymakers and firms/entrepreneurs jointly constructing entrepreneurial ecosystems (Bramwell et al., 2019; Brooks et al., 2019) or "microsystems of innovation" (Periánez-Forte et al., 2016). In these processes, firstly the dispersed and fragmented knowledge should be integrated and combined in order to foster the exploration process, and secondly, information about the potential of the considered domain should be obtained. Moreover, these processes are crucial to establishing priorities within any territory's smart specialisation strategy, allowing 
the system to reorient and renew itself (Foray, 2015; Isaksen et al., 2018; Brooks et al., 2019).

The previous arguments underscore the need for a relevant change in the way policymakers participate in smart specialisation processes and, more specifically, in EDPs. Governments should not play the "omniscient planner" role, but rather they should use their extroversion and network skills (Nikiforou et al., 2020) and capabilities (Shu et al., 2018) to enable, sustain, and guide the participation of stakeholders (firms and entrepreneurs) across the different stages of the policy-making process (Foray, 2015; Foray \& Goenaga, 2013). In that sense, Foray et al. (2012) specifically refer to boundary spanners when referring to people or organisations that government bodies should include and have the interdisciplinary knowledge or proven experience in interaction with different actors for helping to moderate the process:

Hence, they can facilitate new connections across sectors, foster new conversations between disciplines, and inject novelty into the process. This in turn helps to overcome the sectoral and disciplinary silos that reproduce old habits and routines, locking regional economies into their traditional paths of development (Foray et al., 2012: 42).

In fact, the new role of the government should break away from traditional policy intervention and guard itself against the intellectual logic imposed by the principalagent model (Esparza-Masana, 2021; Gianelle et al., 2016; Lepore \& Spigarelli, 2018). As Müür (2021) suggests the capabilities of the intermediary agents and their complementarity when creating interaction dynamics among territorial actors can explain the differences in the success of the different S3 and now S4 strategies and their corresponding EDPs. In this regard, Mieszkowski and Kardas (2015) stress that public agencies should have a more active role when being an intermediary in less advanced territories.

\section{Conceptualisation of the New Role for Policymakers in EDPs}

In the previous section, we argued that policymakers need to develop a new role if they are to maximise the potential of EDPs through collaborative governance. In this section, we conceptualise this new role, first in the context of the smart specialisation literature and then in the context of action research for territorial development, where we call this new role facilitation and the policymakers that perform it facilitative policymakers.

\section{Learning: the Core of the New Role in the S3 Literature}

In 'Entrepreneurial Discovery Processes: in Search of a New Role for Policymakers in Dialogue with Firms and Entrepreneurs,' we already situated learning at the core of the new facilitation role. Learning has sometimes been interpreted as a clarification of concepts, the production of clearer information, or the integration of reliable 
data in the reflection process. We go beyond these perspectives by interpreting learning as the development of individual and collective capabilities (Estensoro \& Larrea, 2016; Larrea et al., 2019). Learning is not a new function, but we argue that there is a renewed emphasis on learning in the face of new and broader institutional and governance challenges emerging within the smart specialisation framework, including S4 (McCann \& Ortega Argilés, 2016; Brooks et al., 2019; McCann \& Soete, 2020; Esparza-Masana, 2021). Learning is also necessary to respond to the complexity of smart specialisation beyond the technological dimensions.

The interpretation of learning as developing the capability to deal with the complexity of broad institutional and governance contexts is related to having a deeper insight into the granularity of engagement (Kroll, 2015; Todeva \& Ketikidis, 2017). To be able to grasp this granularity, governments need to have a better knowledge of the structure of their priority sectors as well as comprehensive lists of innovation actors, leading entrepreneurs, and influential local stakeholders. However, knowledge and lists are not enough, and in order to develop individual and collective capabilities, the conception of learning must evolve from a focus on products (data, reports, lists) to a focus on processes. All this concurs with the understanding of the EDP as a system-level change process (Brekke, 2020; Isaksen et al., 2018). As argued by Brekke (2020, p. 10), 'the EDP process and the entrepreneurial systemlevel role are intended to be sustainable over time, allowing the actors in the RIS to continuously build new interactive learning and knowledge-sharing capabilities which will attract new and related knowledge for diffusion into the regional industry community'.

The learning process in the EDP takes place within the continuous flow of business intelligence, enabling the selection of strategic priorities and the development of strategic partnerships and collaboration (Todeva \& Ketikidis, 2017). Furthermore, learning, as a process, requires not only that the vision of each actor involved is taken into account (Roman \& Nyberg, 2017) but also that there is a process of shared reflection and action which will depend upon trust, openness, and transparency (Rodríguez-Pose \& Wilkie, 2015; Brooks et al., 2019).

Another feature of learning in an EDP is its contextual nature. Given that collective capabilities are different in each place, the individual capabilities to conduct EDPs also differ. Political habits, practices, and routines for policymaking and formal and informal institutions, which vary from place to place, are significantly important when it comes to the degree of efficacy and efficiency with which EDPs can be implemented (Mieszkowski \& Kardas, 2015; Kroll, 2015; Capello \& Lenzi, 2016; Healy, 2016; Isaksen et al., 2018; Aranguren et al., 2018; Brooks et al., 2019; Lepore \& Spigarelli, 2018; Esparza-Masana, 2021; Müür, 2021). Therefore, learning processes in EDPs are based on the territory's assets, capabilities, and weaknesses (McCann \& Ortega Argilés, 2014). The policymaker's role is thus to create learning processes for the development of these new capabilities.

To guarantee that learning in the EDP goes beyond the discourse and impacts of how policies are enacted, policymakers need to avoid judging the process from 'the emperor's new clothes' perspective (Morgan, 2017; Nissinen, 2017). Learning is not the replication of certain discourses but the transformation of practice. Accordingly, public administrations have to undergo processes of self-discovery in order to 
comprehend the obstacles of EDPs and deal with the intractable problems of public sector governance, failure, feedback, and learning (Morgan, 2017).

One of the features of action learning is continuous evaluation. Hence, monitoring is included among the tasks of policymakers to be able to evaluate the actions and decisions taken within the process and also to assess their own role (PeriánezForte et al., 2016; Gianelle et al., 2016; Esparza-Masana, 2021; Müür, 2021).

Considering that this paper focuses on one specific type of EDPs, which are those developed through collaborative governance, learning is a collaborative endeavour that can bring individual, but also collective action as a result.

\section{Facilitation: Encompassing the Features of the New Role}

One of the particular features of smart specialisation is that entrepreneurs (actors from the quadruple helix) are at the centre of the policy process. One of the main challenges of policy makers in this context is that in order to generate EDP processes, it is not enough that they, policy makers, learn. Besides, they have to generate the conditions for entrepreneurs to learn. Learning by entrepreneurs, following the definitions in the previous section, means that entrepreneurs reflect, decide, and act. In order to tackle this challenge, we define the facilitator as someone who, at a specific moment during the EDP, takes on the task of creating the conditions that will enable entrepreneurs to reflect, decide, and act (Costamagna \& Larrea, 2018).

In this section, we share the framework on facilitation (Costamagna \& Larrea, 2018) that inspired the definition of the roles for facilitative policymakers in the case. The functions policymakers should fulfil in their new role are the following:

(a) Creating Spaces for Dialogue

A dialogue is not merely a conversation but also a transformation process. This function entails not only making decisions about who should participate (Nissinen, 2017; Grillo, 2017; Rodríguez-Pose \& Wilkie, 2015; Martínez López \& Palazuelos Martínez, 2015; Mieszkowski \& Kardas, 2015) but also which role each person should play, what the aims of the space are, and the rules of the game. Facilitators work for the connection of a wide network where they encourage collaboration (Müür, 2021).

(b) Constructing a Shared Vision

The dialogue aims to generate a shared vision that enables entrepreneurs to take action, although not necessarily together. We already argued that collaborative learning may lead both to individual and collective action. Facilitative policymakers and entrepreneurs jointly construct a shared language that allows them to understand one another and draw up a vision of the ideal future (Nissinen, 2017; Periánez-Forte et al., 2016; Roman \& Nyberg, 2017). This is part of the right social conditions referred by Lepore and Spigarelli (2018) for the development of the innovation eco-system for EDP. 
(c) Managing Situations of Conflict

Conflict management is closely linked to the process of dialogue. One of the main challenges that facilitative policymakers encounter in EDPs is that potential entrepreneurs frequently keep their conflicts on a tacit level in order to avoid being vulnerable. Even more taking into accounts that as Rodríguez-Pose and Wilkie (2015) and Müür (2021) argue, each of the involved stakeholders participates according to their own interests and motivations.

(d) Building Relationships of Trust

Alongside the creation of spaces for dialogue and a shared vision, building relationships of trust is another fundamental function of the facilitative policymaker as, indeed, trust is something that must be earned in the medium and long term. Openness and transparency are key conditions for building trust (Rodríguez-Pose \& Wilkie, 2015; Mieszkowski \& Kardas, 2015; Brekke, 2020). Likewise, informal mechanisms can be considered as vehicles to build trust (Lepore \& Spigarelli, 2018).

(e) Creating a Shared Agenda

Shared agendas are a tool for moving from reflection to action and do not necessarily require formal documents or detailed action plans. They can be drawn up once sufficient agreement has been reached among policymakers and/or the entrepreneurs on the actions to be carried out. There is a wide variety of actions and decisions that can be taken within EDPs (Periánez-Forte et al., 2016).

(f) Connecting the EDP with Outside Expert Knowledge

While we frequently simplify things by saying that the facilitative policymaker fosters the dialogue with entrepreneurs and among them, it is also important to open up this dialogue to outside experts and networks (Müür, 2021). These experts can include academics, researchers, or consultants, but outside entrepreneurs with relevant experience in a specific area of the EDP can also participate and are crucial for developing connectivity (Aranguren et al., 2018; Todeva \& Ketikidis, 2017; Uyarra et al., 2018; Virkkala et al., 2017). Rissola and Sörvik (2018) argue, for example, how Digital Innovation Hubs (DIHs) are becoming relevant initiatives for connecting smart specialisation processes with outside experts and networks.

(g) Linking Reflection and Action

When playing this role facilitative policy makers help entrepreneurs on continuous transitions from reflection to action, and once action is taken, from action to reflection on that action. This involves the capability of bridging the gap between thinkers and doers in the EDP (Santini et al., 2015). 


\section{The Case and Methodology: Action Research for Developing Facilitation Capabilities Within the Bilbao Urban Smart Specialisation Strategy}

\section{Introduction to the Case of Futurable}

The innovation and smart specialisation strategy of the municipality of Bilbao (iBilbao2020) focused on three priority areas: cultural and creative industries, knowledge-intensive business services (KIBS), and the digital economy. The Bilbao Next Lab is a policy laboratory created to address these priorities, and the action research process outlined in this section is one of this laboratory's activities.

One of the main challenges taken on by the Bilbao Next Lab is to develop the capabilities of policymakers of the city council and the city development agency in order to facilitate EDPs. This was the goal set for the action research process, which focused mainly, though not exclusively on Futurable, a pilot EDP program focusing on wearables technologies.

By combining action research and EDP, we set the focus on the relevance of learning processes in EDP. Besides, following one of the specificities of Bilbao Next Lab, the paper focuses on policy approaches to EDP based on collaborative governance, which makes trust and shared vision relevant dimensions of the process (Ansell \& Gash, 2008). We are aware that this is a specific type of approach, as EDPs can also be developed through processes by individual entrepreneurs. When referring to the roles of policy makers in this paper, we refer to their roles when facilitating EDP in contexts of collaborative governance. We thus acknowledge that collective learning as addressed in this paper is relevant for EDP only when they share this collaborative feature. Ansell and Gash (2008) define collaborative governance as 'a governing arrangement where one or more public agencies directly engage non-state stakeholders in a collective decision-making process that is formal, consensus-oriented, and deliberative and that aims to make or implement public policy or manage public programs or assets' (p. 544). This definition responds to the aims of Bilbao Next Lab when addressing EDP.

This approach to policy making that integrates also social researchers in a wider collaborative governance scheme with territorial stakeholders requires from policy makers an active role through the entire process. It is important to note that in order to respond to the principles of action research and collaborative governance, policy makers are required to participate through the process; however, this should not mean that the final outcome is determined by them beforehand. The dialogue and negotiation process between stakeholders and policy makers, facilitated by researchers, must be a process that unfolds in an emergent manner, through learning and negotiation. This was the attempt in the process, although the case shows that this is a difficult endeavour because there are limits to participation and policy makers need to make decisions that might be close to strategies of picking winners. We interpret that making these dilemmas and challenges explicit is what makes the framework proposed more actionable, as it helps policy makers and researchers anticipate problems that are seldom typified in academic contributions. 
Here, we analyse the case of Futurable in the period from March 2018, when the process started, until February 2019, when policymakers left the process. During this period, policymakers facilitated the organisation of eight workshops whose participants were potential entrepreneurs from the University of the Basque Country, Tecnalia (technology centre), Camp Tecnológico (training centre in digital technologies), and three firms (Bizintek, Emerid, and Wearable Factory Project). The facilitation team included five policymakers from the city development agency, and this case study examines their role.

The emphasis in our paper, however, is not on this entrepreneurial discovery process but on the capability development process that was inspired by the needs expressed by the policymakers after participating in this EDP and which was conducted through action research. We concentrate on this particular process because it was in this context that policymakers reflected on their roles when enabling the EDP. In the interviews with policymakers that participated in that process, the following results were highlighted:

(a) Collaboration between potential entrepreneurs had been fostered. Policymakers in charge of the EDP recorded up to seven connections between the participating potential entrepreneurs which could lead to future collaboration.

(b) Policymakers developed EDP design capabilities.

(c) Policymakers developed facilitation capabilities: 'In this process, we have learnt how to work as facilitators of these courses of action, which provides us with a background for the processes we are about to start under the new directorate' (these comments are related to the decision made by new politicians to initiate four new EDPs in January 2020).

This paper focuses on the third type of result. More specifically, it looks at the capability development process that helps define the roles to be played by the facilitative policymakers in EDPs in general and in Futurable in particular.

\section{Methodological Approach in the Case: Action Research}

Action research is 'an orientation to knowledge creation that arises in a context of practice and requires researchers to work with practitioners. Unlike conventional social sciences, its purpose is not primarily or solely to understand social arrangements, but also to effect desired change' (Bradbury-Huang, 2010, p. 93). Action research has developed in multiple fields, such as education, health, or organisational development, and in the last decade, there is increasing interest in action research processes between with policy makers in the context of policy development (Bartels \& Wittmayer, 2018; Karlsen \& Larrea, 2018). Some of these contributions specifically focus on action research with policy makers in the context of city development (Estensoro, 2020). In these type of action research processes, researchers facilitate knowledge cogeneration processes through which: 
(a) Policy makers develop awareness of what the new roles described for them in the literature actually mean in practice

(b) Such roles are discussed, negotiated, and played, generating contextual versions of what the literature describes in more general terms

(c) Researchers generate process knowledge, which is knowledge about how to make the existing theories an conceptual frameworks actionable

Using this methodology, the policymakers facilitating Futurable were able to reflect on their role(s) in action (they were not exclusively theoretical reflections) and thus generate new knowledge on these roles in the context of application (i.e., reflection was directly transformed into decisions and actions). The methodology consisted in combining the action researcher's process knowledge (based on action research) with expert field knowledge taken from the literature and policymakers' experiential knowledge in developing the Futurable process. The expert field knowledge was used to discuss what an EDP is, what it meant for Futurable, and how it would be facilitated in this process. The contributions discussed with this aim were Foray et al. (2012), Foray (2015, 2016), Aranguren et al. (2016), Periánez-Forte et al. (2016), Estensoro and Larrea (2016), Grillo (2017), Rodríguez-Pose and Wilkie (2015), and Gianelle and Kleibrink (2015). Facilitation was also discussed based on Costamagna and Larrea (2018).

Using these action research workshops as a basis, a document titled 'How to facilitate an EDP?' was published by the research institute which the action researcher belonged to, and Bilbao Ekintza, the city development agency. Together with other presentations and minutes and notes taken at the workshops, this document constituted the source of data for writing the case study. This document shares the knowledge co-generated in the specific case of Bilbao, which is of a more contextual nature and more actionable than the contributions from literature discussed and complements them with more actionable knowledge. To fully document the perspective of facilitative policymakers on this process and its subsequent impacts, we conducted three interviews with policymakers leading the Futurable process (12 March, 16 April, and 4 December 2019).

The goal with this paper is to bring now the contextual knowledge from the case into a more conceptual form, so that we can make a contribution to the literature.

\section{Findings: Roles of the Facilitative Policymakers in Futurable}

In this section, we share the results of the action research process embedded in Futurable for capability development. Participants considered that the first step for developing their capabilities was to have a clear definition of their roles, and they agreed upon the following five: 


\section{(a) Building Capabilities for Facilitation}

One of the distinctive features of Futurable is that policymakers included their own training and capability development process as one more dimension of the EDP. This was a critical decision that aimed to overcome a frequent contradiction in EDPs: policymakers are often invited to take on a new role without previously developing the capabilities to be able to play it. The following quote extracted from meeting minutes illustrates this:

We need a minimum amount of knowledge about wearables to able to facilitate this process... having a small but necessary amount of knowledge is enough, our role being to facilitate. So, with the co-construction of knowledge as an aim..., we also have to learn how to get involved in the discovery process.

\section{(b) Engaging Entrepreneurs by Constructing a Shared Vision}

A second capability which policymakers had to develop was to involve entrepreneurs by constructing a shared vision. Experiments were made with individual meetings between policymakers and entrepreneurs and with storytelling to increase involvement. Among the issues defined collaboratively to develop a shared vision were the technological field to be explored, the selection of other entrepreneurs that could participate, the roles of the entrepreneurs, the rules of the game in the process, the prioritisation criteria, and the actions to be implemented. We illustrate this part with several quotes from the meetings:

We're meeting them [policymakers referring to entrepreneurs] individually to find out what their perspective is on the process, especially the most active and committed ones for those critical moments when decisions have to be made to continue in one direction or another.

All the actors involved, including us, must know the mechanisms with which to influence the others in a transparent manner.

Confidentiality issues are one of the main concerns in these kinds of processes, and the rules of the game must be clear... We devoted a huge part of the meeting to proposing a set of rules on which participants could agree.

We [facilitative policymakers] are the ones who know, in detail, the differences among their [entrepreneurs'] perspectives; they are not always aware of these differences, but we are, and so our role is to find the minimum common ground they share and upon which we can build collective action.

\section{(c) Designing and Facilitating Meetings}

Designing the meetings and later facilitating them was the core role assigned to the facilitative policymakers. In each stage of the EDP, the design and facilitation of meetings had to be adapted to specific circumstances. The following stages were identified by the participants in an emergent process: (1) creating the team of 
facilitative policymakers and agreeing on their roles, (2) identifying opportunity areas and market niches, (3) building the links between supply and demand (technological providers and firms), and (4) reinforcing the ecosystem within specific technological domains. Also, there were some common challenges regarding this role, which we identified in all the stages and that we share below together with the quotes of the policymakers:

The decision on whether or not to outsource facilitation to a consultancy firm:

If we engage a consultancy firm for the facilitation [of meetings], the facilitative role of the agency will be invisible... we must look after our visibility... it is a matter of empowerment too.

The self-confidence required to be able to facilitate the meetings:

The specific facilitative role we play [in meetings] depends on our own capabilities and personality... you need to have confidence in yourself. It is also a matter of feeling sure.

The methodological underpinnings of facilitation:

First of all, the aim of the dynamics [of the meeting] must be clear, and the methodology must pursue that aim, in coherence with our facilitation approach.

The need to envisage the process that lies ahead:

Even though I was happy with the results of the previous workshop, after each one, I already had to start thinking about the next one... in fact, dynamisation is not the most difficult part; the most difficult part is knowing what to do next.

(d) Monitoring and evaluating

As has also been reported by the literature on EDPs, monitoring and evaluation are considered critical steps in the learning process. The following quotes show how facilitative policymakers reflected on it:

Exactly when we bring this discussion to the group [entrepreneurs] is important... this cannot be done when the process has just started... we cannot ask them to think about monitoring when they haven't yet seen any results.

This is completely different from how we've evaluated the agency's activity until now... we've never monitored our role before, and now we need to show that we're capable of contributing, as facilitators, to make EDPs possible.

Policy learning requires that we're honest and critical towards ourselves... this is not a competition about who achieves the best result, and our managers should also aim for more transparency. 


\section{(e) Systematising}

This role aims to document the whole process; that is, not only what happened during the meetings, but also to construct a more elaborate narrative of the lessons learnt. Here again, it is a role closely connected to the interpretation of EDPs as learning processes, and it is clearly influenced by the action research methodologies used in the case. The following quote illustrates this perspective:

The process requires different types of systematisation documents depending on the stage of the process and the specific needs of participants.

\section{Discussion and Conclusions}

Here, we answer the twofold research question of this paper: What are the roles of facilitative policymakers in EDPs? What are the features that make these roles actionable? To do so, we connect the literature on EDPs and facilitation, which we reviewed in the first part of the paper, with the case of Futurable in Bilbao, where the concepts were tested through co-generation. Figure 1 synthesises the roles, which are arranged chronologically, although this does not mean that the followed approach was linear since the roles were enacted throughout the whole process. We do consider, however, that this chronological order can help convey the emergent nature of EDPs.

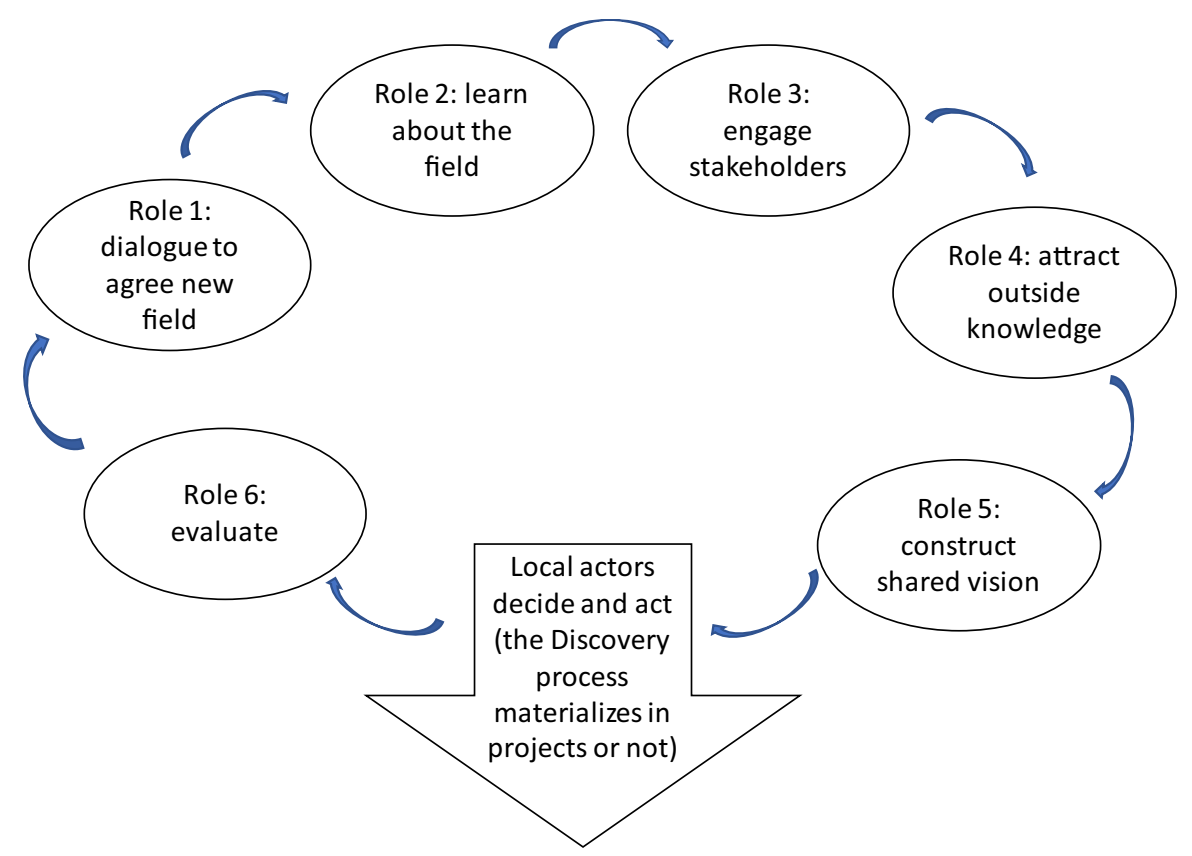

Fig. 1 The six roles of facilitative policymakers in EDPs 
Our objective with the synthesis shown in Fig. 1 is to take the roles co-generated in the Futurable process to a conceptual discussion, which is then linked to the literature presented at the beginning of our paper. We do this keeping the focus on the features that made these roles actionable. This means that we seek a balance where we conceptualise and reduce the context specificity of the case without losing the actionable nature gained through the experimentation of the concepts in practice. In each section, we have combined the discussion and our conclusions.

\section{Role 1: Choosing the Field to be Explored}

This role is enacted in a complex stage of the process, and it rests on a dilemma. The aim of EDPs is to determine which areas should be concentrated on to be able to support entrepreneurial activity through research, development, and innovation policies. This discovery emerges from the dialogue with entrepreneurs. However, given that the number of potential entrepreneurs that policymakers can have a dialogue with is limited, the following dilemma arises: how can policymakers choose the right potential entrepreneurs to participate in the dialogue spaces?

In the Futurable case, the proactiveness of entrepreneurs, together with the specific field pertaining to digital technologies prioritised in the S3 framework, created favourable conditions to make a decision on the field to be explored. In order to fulfil their facilitative role, policymakers must make a continuous effort to keep the dialogue going with potential entrepreneurs in the prioritised areas. When potential is detected in a particular field, experimental processes like Futurable may then be developed until entrepreneurs are empowered to take over. This role also implies a continuous tension between getting to know new potential entrepreneurs and maintaining the dialogue with those that are already on the radar, while acknowledging that there will always be potential entrepreneurs that will remain off the radar. In this regard, employing tools and their corresponding models that allow this selection to be made in an efficient, transparent and fair way, and avoid other more subjective practices from the past, can be useful for this purpose (Martínez López \& Palazuelos Martínez, 2015).

\section{Role 2: Learning About the Fields Chosen for the EDP}

Learning is the core activity of policymakers who facilitate EDPs. The learning process's goal is to be able to interact with potential entrepreneurs and experts productively and connect their knowledge with the knowledge already gathered for the policy process. This does not mean that facilitative policymakers need to become experts in the field where the EDP is conducted. However, they need to have a minimum knowledge (which must be continuously updated) that helps them build trust and a shared vision with potential entrepreneurs. This knowledge is acquired through an ongoing learning process that combines gaining substance knowledge of the field (often connected to specific technologies, markets, and products) and process knowledge (how to build trust, a shared vision, and common agendas). 
With respect to the case studied, the five policymakers from the city development agency acquired substance knowledge concerning wearable technologies through strategic observatory mechanisms and the interaction with entrepreneurs. They also outsourced the preparation of technical reports and diagnoses. Furthermore, they worked to acquire a type of knowledge that is seldom considered to be related to the field where the EDP is carried out. That is, they participated in knowledge cogeneration processes with social researchers to gain insight into how to build trust and a shared vision with the specific community of entrepreneurs involved. Although it is rarely taken into account, this soft and contextual knowledge can be crucial when it comes to making EDPs feasible.

\section{Role 3: Engaging Entrepreneurs}

This role requires selecting the entrepreneurs to be invited to the EDP by contacting them beforehand to ensure a certain degree of commitment to the process on their part.

In the Bilbao case, it was also essential that policymakers discussed with the entrepreneurs how the process was expected to develop since a shared design of it would favour the EDP's sustainability. In fact, the experience of Futurable has shown the value of policymakers and entrepreneurs in co-defining together the list of participants, their roles, the rules of the game (related to issues like confidentiality and sharing information), and the corresponding decision-making mechanisms. It might initially feel like a waste of time, but it helps entrepreneurs appropriate the EDP, so to speak, and thus, they become more engaged.

The other side of the coin is that, to engage entrepreneurs in this way, facilitative policymakers need to be ready to share part of their power when decisions are made concerning the process. This is one of the most challenging aspects of the facilitation we named in the theoretical section the new role of policymakers in smart specialisation and EDPs.

\section{Role 4. Attracting Outside Knowledge}

Stakeholders (policymakers and entrepreneurs) in an EDP can benefit from their exposure to knowledge and ideas from outside their local environment throughout the process. Their knowledge about the particular field and potential innovations, albeit relevant, must be challenged by external knowledge in order to guarantee there is no risk of endogamy.

If we take the Futurable experience in Bilbao, the knowledge of entrepreneurs concerning wearable technologies played a crucial role in building a shared vision of the variety of technologies among all participants. However, it was when firms potentially demanding wearable technologies in the security and health sectors entered the scene that the new applications became clear. In fact, these applications could not have been conceived exclusively by the initial group of policymakers and entrepreneurs. Through this example, we have learned that outside knowledge helps 
connect the supply and demand of the technology, although this is not necessarily always the case.

Thus, facilitative policymakers need to detect what type of external knowledge can challenge the one already existing in the EDP and bring it into the process, their role being to incite local entrepreneurs to interact with external actors who have a different type of knowledge.

\section{Role 5. Developing a Shared Vision}

Many attempts at participatory or collaborative policy processes fail because although participants who are willing to go ahead with the process will meet together, they cannot take it to the next step. As a consequence, stagnation is one of the main fears of facilitative policymakers entering experimental processes.

The case of Bilbao shows the relevance of developing a shared vision that prepares the ground for subsequent actions. The celebration of the workshop on wearables for safety and health is an example of this type of action.

The explicit willingness to continue with a process must be viewed in contrast to the potential implicit conflicts among the participants in the EDP. Implicit conflicts are often at the core of these processes' stagnation, which often go into standby for no apparent reason. It is the role of facilitative policymakers to pay attention to these potential conflicts and help entrepreneurs make them explicit, as long as adequate conditions exist to solve them constructively.

\section{Role 6. Monitoring, Evaluating, and Systematising}

Monitoring is a relevant aspect for the facilitation of EDPs as it leads to the evaluation not only of the actions and decisions taken in the technological field, but also of the facilitation itself (Gianelle et al., 2016; Periánez-Forte et al., 2016).

The Futurable case described in this paper has confirmed the need for monitoring and has shown the relevance of properly defining which actors should engage in monitoring and evaluation. In the case of Futurable, apart from the entrepreneurs taking part in the EDP and the team of facilitative policymakers, the president and the CEO of the agency were also involved.

The main lesson learnt from this process regarding the roles of facilitative policymakers is that monitoring systems should include process indicators to complement input and result indicators. However, the process indicators are sometimes operationalised through indices such as the number of meetings and the number of participants. And the Bilbao experience has shown us that it is difficult to attain a proper evaluation exclusively through these quantitative indicators and also that the systematisation of experiences can be used as a methodology to develop evaluation processes with a higher impact on learning. Systematisation is a process where lessons learnt are extracted by reflecting on a previously documented process. In the case of the Futurable project, this process was facilitated by social researchers and the report on 'How to facilitate EDPs?' mentioned further above. Facilitative policymakers can improve the EDP by integrating systematisation into the monitoring and evaluation processes. 


\section{Final Reflections on the Gap Between Thinkers and Doers}

The methodology used in the case studied was action research, which means here that while policymakers were facilitating the learning process of entrepreneurs, social researchers were simultaneously facilitating the learning process of policymakers.

In smart specialisation and EDPs, policymakers are no longer expected to have the right data on their desk with which they can make the right decision alone on priorities and design the right policy to support prioritised fields. The nature of EDPs requires that facilitative policymakers engage in dialogues with potential entrepreneurs to co-generate the policy. However, this does not imply that having good data is irrelevant, but data is simply one more input to the EDP, together with process and experiential knowledge. The right knowledge is the one cogenerated by participants in the EDP, and such knowledge is generated in action, breaking the barriers between reflection and action.

In these contexts, what do policymakers require from social researchers? Researchers provide smart specialisation processes with a wide array of contents, such as diagnoses that justify the need for smart specialisation policy, proposals with the main objectives of smart specialisation, guidelines for its design and implementation, and case studies and evaluations. In most S3 processes, social researchers have been external observers that diagnosed, analysed, explained, and made recommendations. However, the participatory nature of EDPs also raises questions concerning the roles to be fulfilled. That is to say, if policymakers are interacting with territorial entrepreneurs and not analysing or making decisions at their desks, should we (social researchers) provide them with inputs for reflection at the workplace? The Futurable case created a space where social researchers were able to experiment with interactive and participatory research approaches. Yet the fact is that knowledge on the facilitative role of policymakers in the EDP was not developed at researchers' desks to be later transferred to policymakers for its implementation; it was actually co-generated in the workshops where policymakers made real-time decisions on the EDP.

Thus, our last reflection is that besides offering policymakers an opportunity to experiment with new approaches to innovation policies, EDPs also give researchers the chance to experiment with new approaches to innovation research. The main contribution of this paper is that the knowledge shared in the previous sections is not the result of analysing the EDP process by social researchers, but it is the result of co-generation in the context of application. This means that the roles have not been defined by researchers from literature for policy makers to apply, nor have researchers analysed a process by policy makers from outside. They have constructed the new knowledge together in action. Consequently, the new knowledge has been generated and applied simultaneously, and thus, it has a more actionable nature than the theoretical concepts discussed at the beginning of the process.

Funding Open Access funding provided thanks to the CRUE-CSIC agreement with Springer Nature. 


\section{Declarations}

Ethics Approval Not applicable.

Consent to Participate Not applicable.

Consent for Publication Not applicable.

Conflict of Interest Not applicable.

Open Access This article is licensed under a Creative Commons Attribution 4.0 International License, which permits use, sharing, adaptation, distribution and reproduction in any medium or format, as long as you give appropriate credit to the original author(s) and the source, provide a link to the Creative Commons licence, and indicate if changes were made. The images or other third party material in this article are included in the article's Creative Commons licence, unless indicated otherwise in a credit line to the material. If material is not included in the article's Creative Commons licence and your intended use is not permitted by statutory regulation or exceeds the permitted use, you will need to obtain permission directly from the copyright holder. To view a copy of this licence, visit http://creativecommons.org/ licenses/by/4.0/.

\section{References}

Ahner, D., \& Landabaso, M. (2011). Regional policies in times of austerity. European Review of Industrial Economics and Policy, 2. Available at: http://revel.unice.fr/eriep/index.html?id=3238

Allen, D. W. E. (2019). Governing the entrepreneurial discovery of blockchain applications. Journal of Entrepreneurship and Public Policy, 9(2), 194-212. https://doi.org/10.2139/ssrn.2919170

Ansell, C., \& Gash, A. (2008). Collaborative governance in theory and practice. Journal of Public Administration Research and Theory, 18(4), 543-571. https://doi.org/10.1093/jopart/mum032

Aranguren, M. J., Magro, E., Navarro, M., \& Wilson, J. R. (2018). Governance of the territorial entrepreneurial discovery process: Looking under the bonnet of RIS3. Regional Studies, 53(4), 451-461. https://doi.org/10.1080/00343404.2018.1462484

Aranguren, M. J., Morgan, K., \& Wilson, J. R. (2016). Implementing RIS3: The case of the Basque Country. Working Paper No. 2016/17, San Sebastián: Orkestra-Basque Institute of CompetitivenessDeusto Foundation. Available at: https:/www.orkestra.deusto.es/en/research/publications/reports/ orkestra-notebooks/989-implementing-ris3-case-basque-country

Bartels, K., \& Wittmayer, J. (2018). Introduction: Action research in policy analysis and transition research. In K. Bartels \& J. Wittmayer (Eds.), Action research in policy analysis. Critical and Relational Approaches to Sustainability Transitions, 1-18. Abingdon, Oxon: Routledge.

Bonomi, S., Sarti, D., \& Torre, T. (2020). Creating a collaborative network for welfare services in public sector. A knowledge-based perspective. Journal of Business Research, 112, 440-449. https://doi. org/10.1016/j.jbusres.2019.11.050

Bradbury-Huang, H. (2010). What is good action research? Why the resurgent interest? Action Research, 8(1), 93-109. https://doi.org/10.1177/2F1476750310362435

Bramwell, A., Hepburn, N., \& Wolfe, D. A. (2019). Growing entrepreneurial ecosystems. Journal of Entrepreneurship and Public Policy, 8(2), 272-292. https://doi.org/10.1108/JEPP-04-2019-0034

Brekke, T. (2020). Challenges and opportunities of building an entrepreneurial discovery process through university-industry interaction: A Norwegian case study. Industry and Higher Education. Advance online publication. https://doi.org/10.1177/2F0950422220978348

Brooks, C., Vorley, T., \& Gherhes, C. (2019). Entrepreneurial ecosystems in Poland: Panacea, paper tiger or Pandora's box? Journal of Entrepreneurship and Public Policy, 8(3), 319-338. https://doi.org/10. 1108/JEPP-04-2019-0036

Capello, R., \& Lenzi, C. (2016). Persistence in regional learning paradigms and trajectories: Consequences for innovation policy design. European Planning Studies, 24(9), 1587-1604. https://doi. org/10.1080/09654313.2016.1177493 
Carayannis, E. G., \& Rakhmatullin, R. (2014). The quadruple/quintuple innovation helixes and smart specialisation strategies for sustainable and inclusive growth in Europe and beyond. Journal of the Knowledge Economy, 5, 212-239. https://doi.org/10.1007/s13132-014-0185-8

Costamagna, P., \& Larrea, M. (2018). Facilitative actors of territorial development. A social construction-based approach. Bilbao: Deusto University Press. Available at https:/www.orkestra.deusto.es/ images/investigacion/publicaciones/libros/colecciones-especiales/Facilitative-Actors.pdf

Detterbeck, K. (2018). Framework document based on existing EDP analyses and regions' experiences. Beyond EDP-Interreg Europe Project Report. Available at http://s3platform.jrc.ec.europa.eu/documents/ 20182/196760/Framework+Document/cb400189-e219-4b01-9f80-1b91ef0cd4e9

Esparza-Masana, R. (2021). Towards smart specialization 2.0. Main challenges when updating Strategies. Journal of Knowledge Economy. https://doi.org/10.1007/s13132-021-00766-1

Estensoro, M. (2020). Action research for urban development: The case of Bilbao in M. Larrea (Ed.) Roots and wings of action research for territorial development. Connecting local transformation and international collaborative learning. Bilbao: Deusto University Press.

Estensoro, M., \& Larrea, M. (2016). Overcoming policy making problems in smart specialization strategies: Engaging subregional governments. European Planning Studies, 24(7), 1319-1335. https:// doi.org/10.1080/09654313.2016.1174670

Foray, D., Goddard, J., Goenaga, X., Landabaso, M., McCann, P., Morgan, K., Nauwelaers, C., \& OrtegaArgilés, R. (2012). Guide to research and innovation strategies for smart specialization (RIS3). Publications Office of the European Union. https://doi.org/10.2776/65746

Foray, D. (2015). Smart specialization: Opportunities and challenges for regional innovation policy. Routledge.

Foray, D. (2016). On the policy space of smart specialization strategies. European Planning Studies, 24(8), 1428-1437. https://doi.org/10.1080/09654313.2016.1176126

Foray, D., \& Goenaga, X. (2013). The goals of smart specialisation (S3 Policy Brief No. 01/2013). JRC Scientific and Policy Reports. Luxembourg: Publications Office of the European Union. https://doi. org/10.2791/20158

Gianelle, C. \& Kleibrink, A. (2015). Monitoring mechanisms for smart specialization strategies (S3 Policy Brief No. 13/2015). JRC Technical Reports, Seville: European Commission, Joint Research Centre.

Gianelle, C., Kleibrink, A., \& Doussineau, M. (2016). Monitoring. In C. Gianelle, C. Kyriakou, C. Cohen, \& M. Przeor (Eds.), Implementing smart specialization strategies: A handbook (pp. 98-113). Luxembourg: Publications Office of the European Union. https://doi.org/10.2791/610394

Gonzalez, R., Llopis, J., \& Gasco, J. (2013). Innovation in the public services: The case of Spanish local governments. Journal of Business Research, 66(10), 2024-2033. https://doi.org/10.1016/j.jbusres. 2013.02.028

Grillo, F. (2017). Structuring the entrepreneurial discovery process to promote private-public sector engagement. In D. Kyriakou, M. Palazuelos Martínez, I. Periáñez-Forte, \& A. Rainoldi (Eds.), Governing smart specialisation (pp. 62-79). London: Routledge.

Hausmann, R., \& Rodrik, D. (2003). Economic development as self-discovery. Journal of Development Economics, 72(2), 603-633. https://doi.org/10.1016/S0304-3878(03)00124-X

Healy, A. (2016). Smart specialization in a centralized state: Strengthening the regional contribution in North East Romania. European Planning Studies, 24(8), 1527-1543. https://doi.org/10.1080/09654313. 2016.1184233

Höglund, L. M. H., \& Lingot, G. O. (2018). Smart specialization in regional innovation systems: A quadruple helix perspective: Smart specialization in regional innovation systems. $R \& D$ Management, $48(1)$, $60-72$.

Isaksen, A., Kyllingstad, N., Rypestøl, J. O., \& Schulze-Krogh, A. C. (2018). Differentiated regional entrepreneurial discovery processes. A conceptual discussion and empirical illustration from three emergent clusters. European Planning Studies, 26(11), 2200-2215. https://doi.org/10.1080/09654313. 2018.1530143

Karlsen, J., \& Larrea, M. (2018). Regional innovation system as a framework for the co-generation of policy: An action research approach. In A. Isaksen, R. Martin, \& M. Tripple (Eds.), New Avenues for Regional Innovation Systems- Theoretical Advances, Empirical Cases and Policy Lessons (pp. 257-274). Springer.

Kirzner, I. M. (1997). Entrepreneurial discovery and the competitive market process: An Austrian approach. Journal of Economic Literature, 35(1), 60-85. Available at https://www.jstor.org/stable/ 2729693 
Kroll, H. (2015). Efforts to implement smart specialization in practice-Leading unlike horses to the water. European Planning Studies, 23(10), 2079-2098. https://doi.org/10.1080/09654313.2014. 1003036

Landabaso, M. (2014). Time for the real economy: The need for new forms of public entrepreneurship. Scienze Regionali-Italian Journal of Regional Science, 13(1), 127-140. https://doi.org/10.3280/ SCRE2014-001007

Larrea, M., Estensoro, M., \& Pertoldi, M. (2019). 'Multilevel governance for smart specialisation: Basic pillars for its construction?' S3 Policy Brief Series. Publications Office of the European Union, Luxembourg.

Lepore, D., \& Spigarelli, F. (2018). Opportunities and challenges in collaborative governance for smart specialization strategies-a systematic review of the literature. Economia Marche Journal of Applied Economics, 37(2), 1-27.

Marinelli, E., \& Periánez-Forte, I. (2017). Smart specialization at work: The entrepreneurial discovery as a continuous process. European Commission Joint Research Centre S3 Working Paper No. 12/2017. Available at: http://publications.jrc.ec.europa.eu/repository/bitstream/JRC108571/ jrc108571_marinelli_perianez_jrc108571.pdf

Martínez López, D., \& Palazuelos Martínez, M. (2015). Breaking with the past in smart specialisation: A new model of selection of business stakeholders within the entrepreneurial process of discovery. Journal of Knowledge Economy, 10, 1643-1656. https://doi.org/10.1007/s13132-015-0271-6

Mazzucato, M. (2013). The entrepreneurial state: Debunking public vs. private sector myths. London: Anthem Press.

McCann, P., \& Ortega Argilés, R. (2014). Smart specialisation in European regions: Issues of strategy, institutions and implementation. European Journal of Innovation Management, 17(4), 409427. https://doi.org/10.1108/EJIM-05-2014-0052

McCann, P., \& Ortega Argilés, R. (2016). The early experience of smart specialization implementation in EU cohesion policy. European Planning Studies, 24(8), 1407-1427. https://doi.org/10. 1080/09654313.2016.1166177

McCann, P., \& Soete, L. (2020). Place-based innovation for sustainability. Publications Office of the European Union, Luxembourg, ISBN 978-92-76-20392-6, https://doi.org/10.2760/250023, JRC121271

Mieszkowski, K., \& Kardas, M. (2015). Facilitating an entrepreneurial discovery process for smart specialisation. The case of Poland. Journal of the Knowledge Economy, 6, 357-384. https://doi. org/10.1007/s13132-015-0242-y

Morgan, K. (2017). Nurturing novelty: Regional innovation policy in the age of smart specialisation. Environment and Planning C, 35(4), 569-583. https://doi.org/10.1177/2F0263774X16645106

Müür, J. (2021). Intermediating smart specialisation and entrepreneurial discovery: The cases of Estonia and Helsinki-Uusimaa. Journal of the Knowledge Economy. Advance online publication. https://doi.org/10.1007/s13132-021-00757-2

Nikiforou, A. I., Lioukas, S., \& Voudouris, I. (2020). Network structure and firm-level entrepreneurial behaviour: The role of market and technological knowledge networks. Journal of Business Research, 106, 129-138. https://doi.org/10.1016/j.jbusres.2019.09.008

Nissinen, M. (2017). Smart specialisation entering the Finnish territory. In D. Kyriakou, M. Palazuelos Martínez, I. Periáñez-Forte, \& A. Rainoldi (Eds.), Governing smart specialisation (pp. 179200), London and New York: Routledge.

Periánez-Forte, I., Marinelli, E., \& Foray, D. (2016). The entrepreneurial discovery process (EDP) cycle: From priority selection to strategy implementation. In C. Gianelle, C. Kyriakou, C. Cohen \& M. Przeor, (Eds.), Implementing smart specialization strategies: A handbook (pp. 14-35). Luxembourg: Publications Office of the European Union. https://doi.org/10.2791/610394

Rissola, G., \& Sörvik, J. (2018). Digital innovation hubs in smart specialization strategies, EUR 29374 EN, Luxembourg, Publication Office of the European Union. ISBN 987-92-79-94828-2. https://doi.org/10.2760/475335

Rodríguez-Pose, A., \& Wilkie, C. (2015). Institutions and the entrepreneurial discovery process for smart specialization. Papers in Evolutionary Economic Geography, 15(23), 1-27. Utrecht University.

Roman, M., \& Nyberg, T. (2017). Openness and continuous collaboration as the foundation for entrepreneurial discovery process in Finnish regions. Management Dynamics in the Knowledge Economy, 5(4), 517-531. https://doi.org/10.25019/MDKE/5.4.04 
Santini, C., Marinelli, E., Boden, M., Cavicchi, A., \& Haegeman, K. (2015). Reducing the distance between thinkers and doers in the entrepreneurial discovery process: An exploratory study. Journal of Business Research, 69(5), 1840-1844. https://doi.org/10.1016/j.jbusres.2015.10.066

Shu, R., Shenggang, R., \& Zheng, Y. (2018). Building networks into discovery: The link between entrepreneur network capability and entrepreneurial opportunity discovery. Journal of Business Research, 85, 197-208. https://doi.org/10.1016/j.jbusres.2017.12.048

Todeva, E., \& Ketikidis, P. (2017). Regional entrepreneurship and innovation management: Actors, helices and consensus space. Management Dynamics in the Knowledge Economy, 5(1), 57-76. Available at https://ssrn.com/abstract $=2952066$

Uyarra, E., Marzocchi, C., \& Sorvik, J. (2018). How outward looking is smart specialisation? Rationales, drivers and barriers. European Planning Studies, 26(12), 2344-2363. https://doi.org/10.1080/09654313. 2018.1529146

Virkkala, S., Mäenpää, A., \& Mariussen, ̊. (2017). A connectivity model as a potential tool for smart specialization strategies. European Planning Studies, 25(4), 661-679. https://doi.org/10.1080/09654313.2017. 1283391

Vivanco, P., Elorduy, J. P., \& Eguía, B. B. (2016). Entrepreneurial discovery as the main vector of specialized diversification: Lessons on how to reach smart specialization. Paper presented at the First Smarter Conference on Smart Specialisation and Territorial Development Organised by the Regional Studies Association and the European Commission Joint Research Centre, Seville, Spain.

Publisher's Note Springer Nature remains neutral with regard to jurisdictional claims in published maps and institutional affiliations. 